\title{
Current Trends in the Use of Cannabis sativa: Beyond Recreational and Medicinal Applications
}

\author{
Micah 0. Omare ${ }^{1}$, Joshua K. Kibet ${ }^{2 *}\left(\mathbb{C}\right.$, Jackson K. Cherutoi' ${ }^{1}$, Fredick O. Kengara ${ }^{1,3}$ (i) \\ ${ }^{1}$ Department of Chemistry and Biochemistry and Africa Center of Excellence II in Phytochemicals, Textiles and Renewable Energy \\ (ACE II PTRE), School of Science and Aerospace Studies, Moi University, Eldoret, Kenya \\ ${ }^{2}$ Department of Chemistry, Egerton University, Egerton, Kenya \\ ${ }^{3}$ Department of Chemistry, Bomet University College, Bomet, Kenya \\ Email: omarmitmicah@gmail.com, *jkibet@egerton.ac.ke, cherutoijackson@yahoo.com, fkengara@maseno.ac.ke
}

How to cite this paper: Omare, M.O., Kibet, J.K., Cherutoi, J.K. and Kengara, F.O. (2021) Current Trends in the Use of Cannabis sativa: Beyond Recreational and Medicinal Applications. Open Access Library Journal, 8: e7132.

https://doi.org/10.4236/oalib.1107132

Received: January 5, 2021

Accepted: June 6, 2021

Published: June 9, 2021

Copyright $\odot 2021$ by author(s) and Open Access Library Inc.

This work is licensed under the Creative Commons Attribution International License (CC BY 4.0).

http://creativecommons.org/licenses/by/4.0/

\begin{abstract}
Cannabis sativa finds application in the medical field as an opioid (medical marijuana) and as a recreational drug despite the fact that it is a prohibited drug substance in many countries. Currently, there are reports on the increasing trends in the number of deaths associated with the use of marijuana. Regardless of these dangers, some countries across the world have legalized the sale and use of marijuana for recreational and medicinal purposes. For these reasons, this review seeks to explore the emerging trends through which marijuana is consumed and the chemicals produced in the course of its use. Furthermore, the use of Cannabis sativa as medicine especially in the management of emerging diseases such a Corona virus disease-2019 (COVID-19) and the perceived harms have been reviewed. Relevant literature was identified from database search published between the period 2012 and 2020 in PubMed, Crossref, Google scholar, Cochrane and Web of Science. The articles were considered relevant if they addressed marijuana (Cannabis sativa) use, its impacts on users and non-users, carcinogenicity, medicinal value and COVID-19 management. A number of methods by which marijuana is used have been identified with each method producing different results among users. The chemicals released during smoking of marijuana and their carcinogenic potential and health effects are reported in this work. Further, Cannabis sativa has found significant use in the management of cancer and human immunodeficiency virus (HIV/ AIDS) to alleviate pain and improve appetite, respectively. Although marijuana is regarded as a prohibited and toxic drug substance, there is limited documentation in literature that extensively reports on its toxicological mechanisms especially its role as a cancer causing agent. On
\end{abstract}


the contrary, most scientific studies have reported its use for medical reasons. Accordingly, there is need for further research on cannabis application as a medicinal drug, investigation on its possibility in the managing of the severe acute respiratory syndrome corona virus-2 (SARS-Cov-2) and its epidemiological concerns. Campaigns for the legalization of cannabis for use in clinical medicine are fundamentally recommended but must take into account possible toxicological concerns, health ethics and psychotic problems.

\section{Subject Areas}

Environmental Health/Public Health

\section{Keywords}

Medical Marijuana, Carcinogenicity, Cannabis, Legalization, SARS-Cov-2 Management

\section{Introduction}

The exponential desire to legalize Cannabis sativa in many countries is an interesting observation that cannot be underestimated. The proponents pushing for the legalization of this drug may have genuine concerns but authorities in government must ensure the drug is prescribed by a competent medical practioner. The grave effects of its unregulated use may outweigh its benefits. Nonetheless, responsible use of this drug may save lives because of its known potency against viral diseases. Generally, Marijuana is the second most widely and illegally abused drug substance across the world after tobacco. This mainly because of the psychoactive effects induced by delta-9-tetrahydrocannabinol ( $\Delta$-9-THC) chemical, indicated as 1 in Figure 1, which is obtained from dried leaves, stems, seeds and flowers of the Cannabis sativa hemp plant [1]. The complexity of Cannabis sativa plant is defined by the presence of various compounds that induce psychoactive action on individuals who consume it.

Currently, over 500 chemical compounds have been identified in marijuana with over 60 cannabinoids which generate more than 2000 compounds in marijuana smoke through a series of pyrolysis reactions [1] [2]. With an exception of the main psychoactive alkaloid in cannabis, other cannabinoids such as cannabidiol (CBD), delta-8-tetrahydrocannabinol (d-8-THC) and cannabinol, designated as 2, 3 and 4 in Figure 1, contribute to its pharmacological effects [3]. The introduction of tetrahydrocannabinol (THC) into the biological system induces a number of effects characterized by alterations in memory, movement, mood, perception and cognition and in some cases increased dopamine release that ultimately produces euphoric sensations and anxiolytic effects [4]. Cannabidiol forms almost $40 \%$ of the cannabis extracts from the Cannabis sativa plant and is mainly found in seeds, stalks and flowers of marijuana plant and offers antipsychotic 


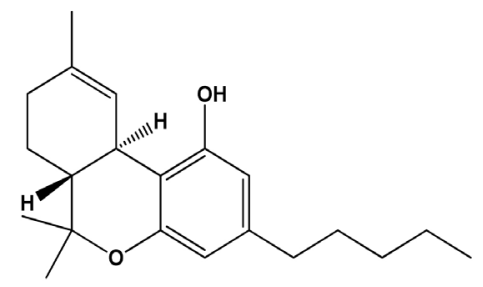

1

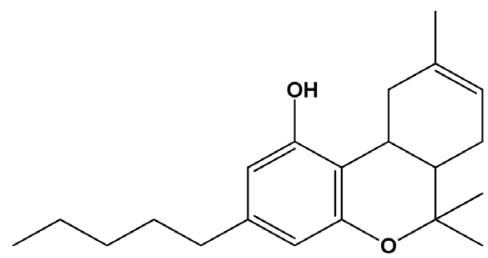

3

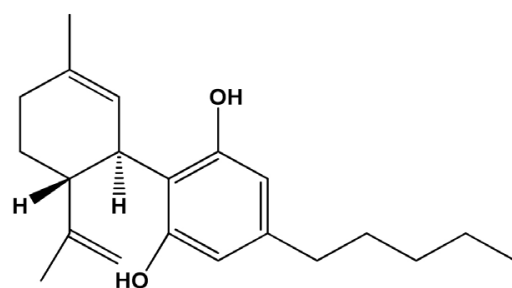

2

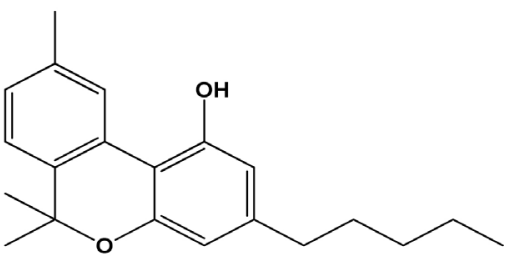

4

Figure 1. Main marijuana cannabinoids molecular structures.

and alerting properties when consumed and this forms the basis for its pharmaco-therapeutic effects [5].

When marijuana is smoked, these compounds find their way into the smokers' body system where they cause a series of disruptive effects among various organs including the pulmonary, respiratory and the central nervous systems [1]. Even though there are minimal reported mortality cases arising from marijuana use among consumers, its increased illegal trading in black markets and consumption patterns precipitates concerns on its potential hazardous effects on human health especially its role as a precursor to cancer development not withstanding that efforts made towards its cessation have been met by a push to legalize its use basically for medicinal concerns. Nevertheless, marijuana smoking has been recognized as a risk factor for a pulmonary function and respiratory complications by a number of systematic and epidemiological studies [6]. The motivation behind this review is to examine the apparent harm and psychotic impacts arising from repeated use of this psychoactive drug substance and the scientific efforts advanced towards its cessation by reviewing selected published articles in different journals and databases. The assessment of documented emerging chemicals from cannabis cigarette smoke and their cancer potency is the primary focus of this work. In addition, scientific efforts taken in order to reduce marijuana toxicity have also been evaluated in this survey. Moreover, marijuana legalization for medicinal purposes as anti-inflammatory, antioxidant, neuroprotective and anticonvulsant characteristics has grown in a number of states and nations in the world upon the assumption that it contains chemical compounds that have potency toward treating a number of illness and symptoms regardless of associated risks [7]. Therefore, the application of marijuana as a pharmaceutical drug has also been reviewed in this study especially its use in the management of the severe acute respiratory syndrome corona virus-2 (SARsCov-2) [8] [9]. These research findings may direct further research in promoting methods that can enhance cessation and control marijuana use and thereby 
promoting a healthy livelihood of the human race. The literature considered for this study is published in English language. After the search on the multidisciplinary databases and google scholar, a number of published reports on the subjects of interest especially on marijuana smoking, toxicity and carcinogenicity were the main search terms.

From the surveyed literature, it can be predicted that in the pharmaceutical industry, cannabis is a potential opioid drug used for relieving pain among cancer patients undergoing chemotherapy, neurological issues and even HIV and AIDS patients who use it to aid in appetite restoration. In line with these characteristics, cannabis is likely to offer more benefits in the medical field if clear handling rules and control measures are ratified by more countries across the world. This will provide room for extensive scientific research on the medical benefits of Cannabis sativa. Figure 2(a) presents Marijuana leaves, whereas Figure 2(b) presents the plant Marijuana, respectively.

\section{Methodology}

Literature search was comprehensively conducted in search engines such as PubMed, Google scholar and online scientific electronic library from March 2020 to May 2020 in accordance with procedures formerly described by [10]. The search was independent and solely done by selecting databases that included original articles published in peer-reviewed journals, books, thesis, dissertations, patents and other reports that covered Cannabis sativa dated until October 2020. Articles published between January 2012 and October 2020 were considered if it had information regarding marijuana toxicity and medicinal properties. Further searches were conducted in google search engine by including general terms such as; marijuana toxicity, cancer, carcinogenicity, dangers, intake methods, throat cancer, smoking, cigarettes and cessation. Where there was need, the search outputs were saved in databases and the authors received notifications for searches that met the search criteria from science direct, PubMed, cross-ref and google scholar.

\section{Results and Discussion}

\subsection{Emerging Trends in Marijuana Intake Techniques}

The effects induced on users by cannabis once consumed are largely dependent
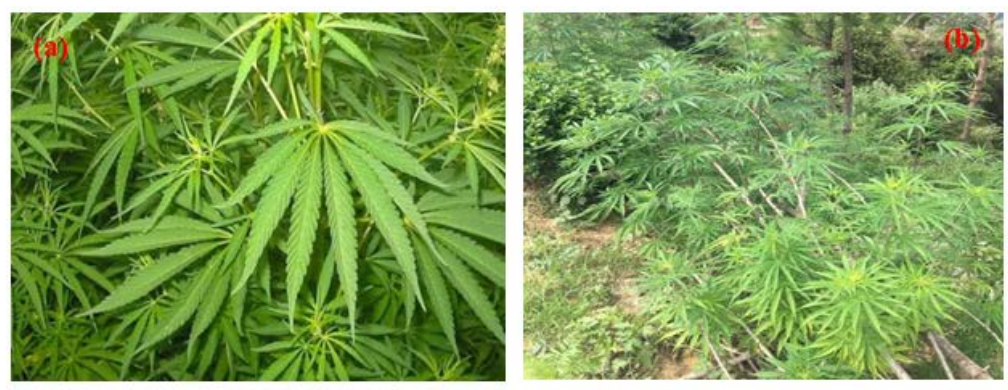

Figure 2. (a) Marijuana leaves and (b) Marijuana plant. 
on the method of delivery. There exists three major cannabis delivery techniques including inhalation, oral and topical, that have been frequently applied for use in different occasions with each method having various designed techniques that offer unique functions and results [11]. Smoking and vaporization are the most prevalent ancient customary inhalation methods that are commonly used and involves the use of hand pipes, water pipes, paper rolls (joints/blunts), hooker and shisha (Table 1) [12]. On the other hand, vaporization technique encompass the usage of vaporizers that steadily heat up cannabis herbs to temperatures high enough to extract THC, CBD and other cannabinoids but too low to expedite the release of harmful toxins such as benzene and toluene as well as odor, which are emitted thereby presumably, lowering the associated health risks throughout the marijuana smoking duration [13].

This technique is widely used and differs from the traditional smoking habit, given that it does not involve combustion. For this reason therefore, vaporization method can be considered safer because it minimizes exposure to the potentially harmful marijuana smoke effluents that could be carcinogenic and toxic to the health of both active and passive smokers [13]. Vaporized cannabis includes the use of vape pens, dab rigs and desktop vaporizers such as volcano

Table 1. Marijuana consumption techniques and popularity trends.

\begin{tabular}{|c|c|c|c|c|}
\hline $\begin{array}{l}\text { Method } \\
\text { of intake }\end{array}$ & Designed Techniques & $\begin{array}{l}\text { Popularity } \\
\text { percentage }\end{array}$ & $\begin{array}{l}\text { Trend in the } \\
\text { last decade }\end{array}$ & Ref. \\
\hline \multirow[t]{3}{*}{ smoking } & $\begin{array}{l}\text { Blunt: cannabis rolled into a cigar } \\
\text { removed of tobacco }\end{array}$ & $40 \%$ & increase & {$[11]$} \\
\hline & Joint: cannabis rolled in paper and smoked & $30 \%$ & Increase & {$[14]$} \\
\hline & Pipe: cannabis smoked in a glass pipe & $40 \%$ & increase & {$[14]$} \\
\hline ingestion & drinks & $60 \%$ & Increase & {$[15]$} \\
\hline ingestion & food & $60 \%$ & Increase & {$[15]$} \\
\hline ingestion & lozenges & $60 \%$ & increase & \\
\hline \multirow[t]{4}{*}{$\begin{array}{l}\text { vaporizing } \\
\text { techniques }\end{array}$} & $\begin{array}{l}\text { Bong: burned cannabis bubbled through } \\
\text { water }\end{array}$ & $13 \%$ & Increase & {$[14]$} \\
\hline & $\begin{array}{l}\text { Hookah: cannabis mixed with flavored } \\
\text { tobacco and smoke bubbled through water }\end{array}$ & $25 \%$ & Increase & {$[12]$} \\
\hline & $\begin{array}{l}\text { Dabbing: cannabis products chemically } \\
\text { dissolved in solvent vapors }\end{array}$ & $25 \%$ & increase & [12] \\
\hline & $\begin{array}{l}\text { G-pen: Cannabis concentrated into wax, } \\
\text { oil, or hash and vaporized through } \\
\text { e-cigarette }\end{array}$ & $26 \%$ & increase & [16] \\
\hline \multirow[t]{3}{*}{$\begin{array}{l}\text { skin and mucosal } \\
\text { surface absorption }\end{array}$} & creams & $18 \%$ & Increase & [11] \\
\hline & patches & $13 \%$ & increase & [17] \\
\hline & sprays & $16 \%$ & Increase & [17] \\
\hline
\end{tabular}


medic vaporizer. In comparison, vaporized and smoked THC have similar pharmacokinetic profiles but on the contrary, vaporizers produce higher THC concentrations compared to smoked cannabis resulting to greater THC concentrations in blood, drug effects, mouth dryness and dry irritated eyes when same doses are smoked and vaped [16]. Oral methods include techniques that administer cannabis through the mouth such as edibles and tinctures. For instance, marijuana edibles include drinks, foods and lozenges which have been infused with THC while tinctures include liquid cannabis extracts consumed by placing 3 - 4 drops under the tongue and gets immediately absorbed into the body system [15]. Consequently, marijuana products are classified as liquids (butane, hash oil, distillate), soft solids (wax, budder), and hard solids (shatter and crumble). A range of marijuana ingestion methods and their popularity is reported in Table 1.

\subsection{Emerging Chemicals from Marijuana}

A good number of scientific researches have extensively identified the chemical composition of marijuana smoke and evidently noted that there exists a close association in chemical composition between second hand marijuana smoke, and tobacco smoke. The outstanding differences lies in the component concentrations variation with remarkably similar chemicals such as nitric oxides and aldehydes which have been proven to cause detrimental health effects [18]. There is substantially little scientific research that has explored the chemical characterization of marijuana cigarette smoke but most of the available studies have focused on determining cannabinoids in marijuana smoke and reported it to contain most toxins, irritants and carcinogens commonly present in tobacco smoke [19]. For instance, when smoked, marijuana releases more tar accompanied by substantially higher concentrations of carcinogens such as benzo[a]pyrene as compared to tobacco smoke, and consequently it has been classified as a secondary carcinogen that possesses approximately $50 \%$ to $70 \%$ more carcinogenic polycyclic aromatic hydrocarbons (PAHs) such as benzo[a]anthracene, benzene and phenols in alongside toxic gases and reactive oxygen species that are 20 times higher in concentration than they are in tobacco [20]. Notably, these variations in carcinogenic compound concentration in marijuana enhance its probability of causing lung cancer in the same way tobacco does, which has been credited as the leading cause of lung cancer in various researches [19]. Nevertheless, it can be presumed that smoking of marijuana is a precursor for respiratory disease and cancer similar to those caused by tobacco smoking, but on the other hand, there is minimal literature demonstrating that marijuana smoking causes cancer [21]. Additionally, it has been suggested that marijuana smoke comprises of particulate matter that is harmful and carcinogenic when inhaled because it contains potent compounds such as volatile organics and aromatic amines [19]. A range of toxic molecular compounds isolated from marijuana and their classification are presented in Table 2. 
Table 2. Some carcinogenic chemical compounds reported present in marijuana.

\begin{tabular}{ccc}
\hline Chemical compounds & Carcinogenicity & Ref. \\
\hline carbon monoxide & Not listed & \\
benzene & Group 1 & {$[22]$} \\
formaldehyde & Group 1 & {$[23]$} \\
polycyclic aromatic hydrocarbons (PAHs) & Group 1, Group 2A and group 2B & {$[24]$} \\
hydrogen cyanide & Not listed & {$[22]$} \\
benzo (a) pyrene (BaP) & Group 1 & {$[25]$} \\
heterocyclic aromatic amines & Not listed & {$[26]$} \\
aldehydes & Group 1 & {$[27]$} \\
phenolic compounds & Not listed & {$[22]$} \\
volatile hydrocarbons, & Group 2A & {$[22]$} \\
toluene & Group 3 & {$[22]$} \\
furan & Group 2B & {$[22]$} \\
2-methylfuvan & Not listed & {$[22]$} \\
isobutylene & Group 1A & {$[28]$} \\
terpenes and terpenoids & Group 2B & {$[29]$} \\
tetrahydrocannabinol & Not listed & \\
cannabidiol & Group 2B & \\
\hline
\end{tabular}

\subsection{Harm Arising from Consumption of Marijuana}

Marijuana smokers are motivated by its psychotropic effects characterized by a pleasurable feeling, euphoria and relaxation which result in psychotic symptoms, cognitive changes, panic reactions and anxiety which have been reported as severe side effects [32]. Epidemiological evidence has linked lung disease, increased respiratory and cardiovascular symptoms, chronic bronchitis and chronic obstructive disease and emphysema to marijuana smoking [33]. In some instances, marijuana use can cause alteration and sometimes loss in memory characterized by slowed reaction time, hampered information processing, un-coordinated motor reactions and performance, and attention deficiency that result in mood disorder syndrome, psychosis and schizophrenia [34]. Accordingly, a review on the effects of marijuana smoking on the lungs found out that prolonged cannabis smoking leads to lung cancer and cancers of the upper aero digestive tract [35]. Moreover, a brief exposure to second hand marijuana smoke leads to acute vascular endothelial dysfunction [36]. Nonetheless, lack of sober mental control due to the detrimental effects of marijuana among intoxicated drivers has been reported to increase the risk of road accidents [37]. The occurrence of these events is hypothesized by the fact that when one smokes marijuana joint, he/she is four times exposed to carbon monoxide and five times more tar deposition than a single tobacco cigarette due to more deep inhalation and longer holding breath times and lack of cannabis cigarette filters [33]. Consequently, psychiatric dis- 
orders among marijuana smokers have been associated with acute and chronic smoking [38]. As a result, young cannabis users are likely to experience a deficiency in mental performance characterized by slowness in information processing, amnesia and deprived attention which adversely affects their learning faculties [39]. In addition, pregnant women who get exposed to cannabis are more likely to experience weakened visualization and dexterity, and may give birth to children that are prone to abnormal behaviors [1].

Once the presence of cannabis is detected in the human central nervous system (CNS), it excites the production of dopamine and endogenous opioids which inhibits the secretion of acetylcholine responsible for pharmacological changes in the brain leading to a decrease of glutamatergic synaptic transmission which causes brain functioning abnormalities among the cannabis smoking communities [39]. The endocannabinoid system receptors, cannabinoid receptor type 1 (CB1) and cannabinoid receptor type 2 (CB2) offer inhibitory function, where $\mathrm{CB} 1$ receptor act on the production of cyclic adenosine monophosphate pathway once they receive a signal from adenyl cyclase inhibitor activation while CB2 receptor plays an important role in blocking inflammatory activity and tissue damage [1]. Therefore, brain structural abnormality has been observed in chronic cannabis smokers with more effects imposed on the grey and white matter density [34]. Moreover, variable brain activity among cannabis consumers has been reported and compared to non-smokers in which greater brain activation is observed in the prefrontal region of smokers while hypo-activation is noted along the left superior parietal cortex due to high concentrations of the two cannabinoids, THC and CBD, THC alters the hippocampal capacity and neurochemistry while on the other hand, CBD defends against toxic variations [40].

Nonetheless, cerebral stroke, one of the leading causes of death has been associated with cannabis intake according to a number of preclinical studies and scientific case reports [41]. Scientifically, neurological stroke and Alzheimer's disease solely result from exposure to reactive oxygen species such as peroxynitrite, hydrogen peroxide, epoxides etc. and oxidative stress pathways that cause tissue and cellular damage, conditions which are largely promoted by cannabis smoking [1]. Accordingly, THC is a potential agent of oxidative stress and a threat in the initiation of ischemic stroke [42]. Reactive oxidative stress compounds can be generated by combustion reactions that occur during marijuana smoking.

\subsection{Proposed Application of Marijuana in the Management of Covid-19}

Pharmacological and toxicological properties of cannabis are contributed by eighteen classes of chemicals which include hydrocarbons, sugars, simple fatty acids, terpenes, amino acids, and nitrogenous compounds [43]. Accordingly, cannabis has been used for treating oncology patients [44], epileptic patients [45], and management of inflammatory bowel disease [46], neurological and psychiatric disorders [34], and sometimes in children to treat autism spectrum disorder, 
fetal alcohol spectrum disorder and in pregnant mothers in the management of hyperemis gravidarum [7]. This has been attributed to the non-psychoactive cannabinoid $\mathrm{CBD}$ which interacts with the $\mathrm{CB} 2$ receptor that gets activated to reduce pain, seizures and inflammations in patients, and sometimes in the management of epilepsy, schizophrenia and post-traumatic stress disorders [1]. Evidently, therapeutic capacity of THC against chronic pain and sclerosis neurological ailments has also been documented [34]. Some studies have reported the application of marijuana in the treatment of HIV patients to improve their food intake and promote their appetite by increasing ghrelin and leptin hormones, and decreasing peptide tyrosine hormone responsible for appetite regulation [47].

In addition, the application of medicinal marijuana in management of corona virus disease 2019 (COVID-19) has been explored by a number of scientific studies. Covid-19 is an infectious disease that occurs as a result of the SARS-CoV-2 virus in humans [48]. This disease had not found any medical cure by the time this review was done. Therefore in the search for a vaccination or cure, the application of Marijuana has been explored by scientists who have given preliminary findings showing that the plant may offer resistance to SARS-CoV-2 [8]. The principle behind this is based on the fact that medicinal cannabis has been used to treat nausea and dementia, thus offering hopes that the angiotensin converting enzyme II (ACE-2) receptor needed by the corona virus found in the lung tissues, oral and nasal mucus, and gastrointestinal tracts can be modulated using cannabis extracts and removed from the biological system in order to inhibit vulnerability against the virus and therefore reduce its infection risks [49]. Furthermore, terpenes from cannabis have exhibited potent characteristics as antiviral agents with the ability to minimize the severity and impact of SARS virus by suppressing the protein responsible for RNA replication and thereby blocking the virus from penetrating the cells [8]. For instance, it has been emphasized that marijuana extracts can reduce or regulate serine protease TMPRSS2, mainly required by the SARS-Cov-2 in order to gain entry into the human host cells [8] [9]. Consequently, cannabis has been reported to be effective in the prevention and treating of COVID-19 even though there are limited scientific studies that have been performed to support or refute these assertions, especially the role played by cannabinoids towards viral therapy [50].

\subsection{Pharmacokinetics of Cannabis sativa}

Cannabis just like any other drug substance once taken into the body system it describes a systematic pathway from the time it gains entry into the body system up to the time it is excreted through series of biological activities that involve absorption, distribution, metabolism and excretion, all which are dependent on the drug bioavailability that determines the onset, duration and the intensity of effects manifested by the drug [51]. Cannabidiol has been put into use under uncontrolled conditions in order to offer therapeutic effects in many occasions thus raising concern on its therapeutic drug monitoring. According to Millar et 
al (2018), CBD has found widespread therapeutic applications but still, there exists lack of data in its pharmacokinetics [52]. The route of administration of cannabis into the human body system determines the rate by which it is absorbed and its metabolism due to variations in consumption of drug concentration [53]. Precisely, when THC is inhaled and assimilated through the pulmonary system, the associated psychotropic effects are manifested within a period of less than 1 minute but reach a maximum after 20 to 30 minutes, but when it is ingested orally, it takes about 30 to 90 minutes for the psychotropic effects to occur approximately reaching a maximum after 2 hours and remain activated in the smoker for 4 to 12 hours depending on the dose smoked [11] [53] [54].

Cannabis inhalation is characterized by puff numbers, residence time and time interval as well as inhalation volume and hold times which greatly influence its bioavailability [54]. In general, cannabis pharmacokinetics is dependent on smoker related factors in addition to chemical properties of cannabinoids and other compounds present in the smoke [43]. Therefore, smoker related factors embracing age, genetic makeup, renal function and sex which vary from different smoking population across the world, greatly determine the extent to which marijuana pharmacokinetic profiles are expressed [51]. Metabolic activities on THC take place particularly in the liver where microsomal hydroxylation and oxidation processes occur [43]. Hydroxylation step involves the conversion of THC into 11-hydroxy-THC under cytochrome P-450 (CYP2C19) complex enzyme catalysis and subsequently, 11-hydroxy-THC which is oxidized to 11-nor-9-carboxy-THC which glucuronates to THC-COOH beta glucuronide that lacks psychotropic properties [43] [55] as illustrated in Scheme 1, before being excreted though kidneys, faecal matter and urine [52].

On the other hand, CBD gets metabolized by isozymes CYP2C19 and cytochrome P-450 3A4 (CYP3A4) through hydroxylation to 7-hydroxy cannabidiol (7-OH-CBD) which is further metabolized, and ultimately excreted through faecal matter and urine [56]. During the elimination process, the half-life elimination

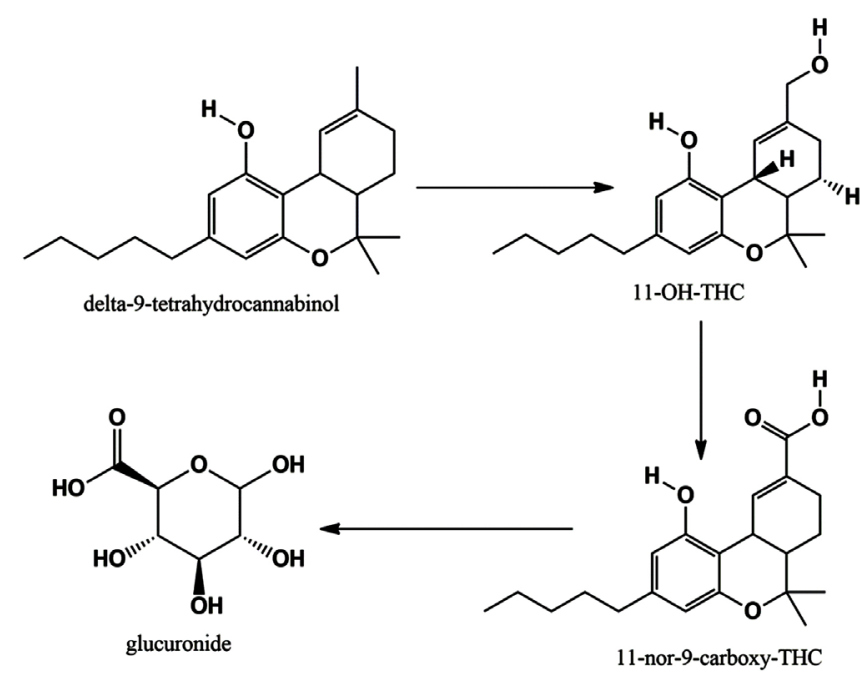

Scheme 1. Delta 9-THC hydroxylation to 11-nor-9-carboxy-THC. 
period for THC and CBD vary depending on how long it takes for equilibrium to be attained between the blood and lipid storage compartment duration [54]. Accordingly, heavy cannabis users exhibit a fairly longer THC elimination halflife of about 22 hours because of slowed redistribution rates from deeper fatty acid compartment tissues [54] [57]. Similarly, CBD has long elimination half-life of about 34 hours once inhaled into the biological system [58].

\section{Conclusion}

This work has demonstrated that cannabis is one of the highly consumed psychoactive drug substance despite its legalization challenges in some countries. The proponents pushing for the legalization of cannabis advance that this drug is important for recreational and medicinal use. Arguably, there is an exponential increase in the rates of cannabis consumption across the world. Numerous techniques that facilitate the consumption of cannabis drug have also increased significantly. Some of the identified consumption techniques include smoking, vaporizing techniques, skin and mucosal surface absorption with each method offering exceptional and dissimilar outcomes. Nonetheless, this drug substance is in many ways considered unsafe for human consumption. There is however, limited research that has expressively reported on the perceived cannabis toxicity and its cancer precursor characteristics. Although various authors have linked cannabis to throat cancer and cancers of the respiratory tract system, there is lack of substantive evidence that establishes the mechanisms by which cannabis and its cannabinoids induce cancer. Instead, other toxic compounds produced during cannabis smoking-carcinogenic polycyclic aromatic hydrocarbons, phenols, toxic gases, and reactive oxygen species (hydroxyl and super oxide radicals) have been identified to be present in cannabis smoke and therefore likely to initiate cell mutation among marijuana smokers. On the contrary, cannabis has been used as an opioid in the management of cancer patients to relieve pain, inflammatory bowel disease, epilepsy, neurological problems and psychiatric disorders. Besides, cannabis has been proposed as a potential lead in the management of COVID-19 disease because of its high potency as an antiviral agent, although more scientific studies and clinical trials are necessary.

\section{Acknowledgements}

The authors are thankful to the Africa Center of Excellence II in Phytochemicals, Textiles and Renewable Energy (ACE II PTRE), Moi University, and Egerton University, Division of Research and Extension for facilitating the success of this review article. Mr. Korir Benjamin of Egerton University is credited for his input in editing the bibliography used in this paper.

\section{Funding}

The authors are grateful to the Africa Center of Excellence II in Phytochemicals, Textiles and Renewable Energy (ACE II PTRE) and Egerton University grant 
\#EU/RE/DVC/072 for co-funding this research.

\section{Conflicts of Interest}

The authors have no competing interests.

\section{References}

[1] Archie, S.R. and Cucullo, L. (2019) Harmful Effects of Smoking Cannabis: A Cerebrovascular and Neurological Perspective. Frontiers in Pharmacology, 10, Article No. 1481. https://doi.org/10.3389/fphar.2019.01481

[2] Borgan, F., Beck, K., Butler, E., McCutcheon, R., Veronese, M., Vernon, A., et al. (2019) The Effects of Cannabinoid 1 Receptor Compounds on Memory: A Meta-Analysis and Systematic Review across Species. Psychopharmacology, 236, 3257 3270. https://doi.org/10.1007/s00213-019-05283-3

[3] Köguel, C.C., López-Pelayo, H., Balcells-Olivero, M.M., Colom, J. and Gual, A. (2018) Constituyentes psicoactivos del cannabis y sus implicaciones clínicas: una revisión sistemática. Adicciones, 30, 140-151. https://doi.org/10.20882/adicciones.858

[4] Cohen, K., Kapitány-Fövény, M., Mama, Y., Arieli, M., Rosca, P., Demetrovics, Z., et al. (2017) The Effects of Synthetic Cannabinoids on Executive Function. Psychopharmacology, 234, 1121-1134. https://doi.org/10.1007/s00213-017-4546-4

[5] NIDA (2021) Is Marijuana Safe and Effective as Medicine? https://www.drugabuse.gov/publications/research-reports/marijuana/marijuana-saf e-effective-medicine

[6] Ribeiro, L.I. and Ind, P.W. (2016) Effect of Cannabis Smoking on Lung Function and Respiratory Symptoms: A Structured Literature Review. NPJ Primary Care Respiratory Medicine, 26, Article No. 16071. https://doi.org/10.1038/npjpcrm.2016.71

[7] Koren, G. and Cohen, R. (2020) Medicinal Use of Cannabis in Children and Pregnant Women. Rambam Maimonides Medical Journal, 11, e0005. https://doi.org/10.5041/RMMJ.10382

[8] Wang, B., Kovalchuk, A., Li, D., Ilnytskyy, Y., Kovalchuk, I. and Kovalchuk, O. (2020) In Search of Preventative Strategies: Novel Anti-Inflammatory High-CBD Cannabis Sativa Extracts Modulate ACE2 Expression in COVID-19 Gateway Tissues. Aging (Albany NY), 12, 22425-22444. https://doi.org/10.20944/preprints202004.0315.v1

[9] Hoffmann, M., Kleine-Weber, H., Schroeder, S., Krüger, N., Herrler, T, Erichsen, S., et al. (2020) SARS-CoV-2 Cell Entry Depends on ACE2 and TMPRSS2 and Is Blocked by a Clinically Proven Protease Inhibitor. Cell, 181, 271-280.E8. https://doi.org/10.1016/j.cell.2020.02.052

[10] Palmatier, R.W., Houston, M.B. and Hulland, J. (2018) Review Articles: Purpose, Process, and Structure. Journal of the Academy of Marketing Science, 46, 1-5. https://doi.org/10.1007/s11747-017-0563-4

[11] Williams, K. (2014) The Different Ways to Smoke and Consume Cannabis.

[12] Healthiest, B.J. (2020) Ways to Consume Weed: Better than Smoking.

[13] Romano, L. and Hazekamp, A. (2019) An Overview of Galenic Preparation Methods for Medicinal Cannabis. Current Bioactive Compounds, 15, 174-195.

[14] NIDA (2019) Marijuana DrugFacts.

https://www.drugabuse.gov/publications/drugfacts/marijuana 
[15] Franklin, R.M., Rosenthal, E. and Franklin, R.M. (2017) Method for Conducing Concentrated Cannabis Oil to Be Stable, Emulsifiable and Flavorless for Use in Hot Beverages and Resulting Powderized Cannabis Oil. US 20160243177.

[16] Spindle, T.R., Cone, E.J., Schlienz, N.J., Mitchell, J.M., Bigelow, G.E., Flegel, R., et al. (2020) Urinary Excretion Profile of 11-Nor-9-Carboxy- $\Delta$ 9-Tetrahydrocannabinol (THCCOOH) Following Smoked and Vaporized Cannabis Administration in Infrequent Cannabis Users. Journal of Analytical Toxicology, 44, 1-14. https://doi.org/10.1093/jat/bkz038

[17] Bruni, N., Della Pepa, C., Oliaro-Bosso, S., Pessione, E., Gastaldi, D. and Dosio, F. (2018) Cannabinoid Delivery Systems for Pain and Inflammation Treatment. Molecules, 23, Article No. 2478. https://doi.org/10.3390/molecules23102478

[18] Holitzki, H., Dowsett, L.E., Spackman, E., Noseworthy, T., Clement, F. (2017) Health Effects of Exposure to Second- and Third-Hand Marijuana Smoke: A Systematic Review. CMAJopen, 5, E814-e822. https://doi.org/10.9778/cmajo.20170112

[19] Graves, B.M., Johnson, T.J., Nishida, R.T., Dias, R.P., Savareear, B., Harynuk, J.J., et al. (2020) Comprehensive Characterization of Mainstream Marijuana and Tobacco Smoke. Scientific Reports, 10, Article No. 7160. https://doi.org/10.1038/s41598-020-63120-6

[20] Ghasemiesfe, M., Barrow, B., Leonard, S., Keyhani, S. and Korenstein, D. (2019) Association between Marijuana Use and Risk of Cancer: A Systematic Review and Meta-Analysis. JAMA Network Open, 2, Article ID: e1916318. https://doi.org/10.1001/jamanetworkopen.2019.16318

[21] Callaghan, R.C., Allebeck, P., Akre, O., McGlynn, K.A. and Sidorchuk, A. (2017) Cannabis Use and Incidence of Testicular Cancer: A 42-Year Follow-Up of Swedish Men between 1970 and 2011. Cancer Epidemiology and Prevention Biomarkers, 26, 1644-1652. https://doi.org/10.1158/1055-9965.EPI-17-0428

[22] IARC (2019) IARC Monographs on the Identification of Carcinogenic Hazards to Humans. https://monographs.iarc.who.int/list-of-classifications/

[23] Swenberg, J.A., Moeller, B.C., Lu, K., Rager, J.E., Fry, R.C. and Starr, T.B. (2013) Formaldehyde Carcinogenicity Research: 30 Years and Counting for Mode of Action, Epidemiology, and Cancer Risk Assessment. Toxicologic Pathology, 41, 181-189. https://doi.org/10.1177\%2F0192623312466459

[24] Abdel-Shafy, H.I. and Mansour, M.S. (2016) A Review on Polycyclic Aromatic Hydrocarbons: Source, Environmental Impact, Effect on Human Health and Remediation. Egyptian Journal of Petroleum, 25, 107-123.

https://doi.org/10.1016/j.ejpe.2015.03.011

[25] Nakajima, D. and Yagishita, M. (2018) Carcinogenicity/Mutagenicity. In: Hayakawa K., Ed., Polycyclic Aromatic Hydrocarbons, Springer, Singapore, 235-244. https://doi.org/10.1007/978-981-10-6775-4_18

[26] Dong, H., Xian, Y., Li, H., Bai, W. and Zeng, X. (2020) Potential Carcinogenic Heterocyclic Aromatic Amines (HAAs) in Foodstuffs: Formation, Extraction, Analytical Methods, and Mitigation Strategies. Comprehensive Reviews in Food Science and Food Safety, 19, 365-404. https://doi.org/10.1111/1541-4337.12527

[27] Tan, S.L.W., Chadha, S., Liu, Y., Gabasova, E., Perera, D., Ahmed, K., et al. (2017) A Class of Environmental and Endogenous Toxins Induces BRCA2 Haploinsufficiency and Genome Instability. Cell, 169, 1105-1118.E15. https://doi.org/10.1016/j.cell.2017.05.010

[28] National Center for Biotechnology Information (2020) Isobutylene. PubChem Database. 
[29] Omare, M., Kibet, J., Cherutoi, J. and Kengara, F. (2020) A Review of the Current Trends on the Use of Cannabis Sativa for Recreational, Medicinal Applications, and Its Toxicological Health Impacts. Authorea, Preprints. https://doi.org/10.22541/au.159318524.43742889

[30] World Health Organization (2018) Delta-9-Tetrahydrocannabinol. World Health Organization, Geneva.

[31] Russo, C., Ferk, F., Mišík, M., Ropek, N., Nersesyan, A., Mejri, D., et al. (2019) Low Doses of Widely Consumed Cannabinoids (Cannabidiol and Cannabidivarin) Cause DNA Damage and Chromosomal Aberrations in Human-Derived Cells. Archives of Toxicology, 93, 179-188. https://doi.org/10.1007/s00204-018-2322-9

[32] Radhakrishnan, R., Wilkinson, S.T. and D’Souza, D.C. (2014) Gone to Pot-A Review of the Association between Cannabis and Psychosis. Frontiers in Psychiatry, 5, Article No. 54. https://doi.org/10.3389/fpsyt.2014.00054

[33] Groce, E. (2018) The Health Effects of Cannabis and Cannabinoids: The Current State of Evidence and Recommendations for Research. Journal of Medical Regulation, 104, 32. https://doi.org/10.30770/2572-1852-104.4.32

[34] Cohen, K, Weizman, A. and Weinstein, A. (2019) Positive and Negative Effects of Cannabis and Cannabinoids on Health. Clinical Pharmacology \& Therapeutics, 105, 1139-1147. https://doi.org/10.1002/cpt.1381

[35] Byers, C. (2017) Marijuana Smoking and the Risk of Developing COPD, Lung Cancer, and/or Chronic Respiratory Symptoms: A Systematic Review. Canadian Medical Association Journal, 180, 797-798. https://doi.org/10.1503\%2Fcmaj.090142

[36] Wang, X., Derakhshandeh, R., Liu, J., Narayan, S., Nabavizadeh, P., Le, S., et al. (2016) One Minute of Marijuana Secondhand Smoke Exposure Substantially Impairs Vascular Endothelial Function. Journal of the American Heart Association, 5, Article ID: e003858. https://doi.org/10.1161/JAHA.116.003858

[37] Hartman, R.L. and Huestis, M.A. (2013) Cannabis Effects on Driving Skills. Clinical Chemistry, 59, 478-492. https://doi.org/10.1373/clinchem.2012.194381

[38] National Center for Biotechnology Information (2020) Marijuana.

[39] Bloomfield, M.A., Ashok, A.H., Volkow, N.D. and Howes, O.D. (2016) The Effects of $\Delta^{9}$-Tetrahydrocannabinol on the Dopamine System. Nature, 539, 369-377. https://doi.org/10.1038/nature20153

[40] Beale, C., Broyd, S.J., Chye, Y., Suo, C., Schira, M., Galettis, P., et al. (2018) Prolonged Cannabidiol Treatment Effects on Hippocampal Subfield Volumes in Current Cannabis Users. Cannabis and Cannabinoid Research, 3, 94-107. https://doi.org/10.1089/can.2017.0047

[41] Wolff, V. and Jouanjus, E. (2017) Strokes Are Possible Complications of Cannabinoids Use. Epilepsy \& Behavior, 70, 355-363. https://doi.org/10.1016/j.yebeh.2017.01.031

[42] Wolff, V., Lauer, V., Rouyer, O., Sellal, F., Meyer, N., Raul, J.S., et al. (2011) Cannabis Use, Ischemic Stroke, and Multifocal Intracranial Vasoconstriction: A Prospective Study in 48 Consecutive Young Patients. Stroke, 42, 1778-1780. https://doi.org/10.1161/STROKEAHA.110.610915

[43] Sharma, P., Murthy, P. and Bharath, M.S. (2012) Chemistry, Metabolism, and Toxicology of Cannabis: Clinical Implications. Iranian Journal of Psychiatry, 7, 149-156.

[44] Ahmed, C., Lee, A., Campbell, A., Garber, G., Palmisiano, N.D. and Worster, B. (2020) The Financial and Psychosocial Impact of Medicinal Cannabis. Thomas Jefferson University, Sydney.

[45] de Carvalho Reis, R., Almeida, K.J., da Silva Lopes, L., de Melo Mendes, C.M. and 
Bor-Seng-Shu, E. (2020) Efficacy and Adverse Event Profile of Cannabidiol and Medicinal Cannabis for Treatment-Resistant Epilepsy: Systematic Review and Meta-Analysis. Epilepsy \& Behavior, 102, Article ID: 106635. https://doi.org/10.1016/j.yebeh.2019.106635

[46] Perisetti, A., Rimu, A.H., Khan, S.A., Bansal, P. and Goyal, H. (2020) Role of Cannabis in Inflammatory Bowel Diseases. Annals of Gastroenterology, 33, 134-144.

[47] Birdsall, S.M., Birdsall, T.C. and Tims, L.A. (2016) The Use of Medical Marijuana in Cancer. Current Oncology Reports, 18, Article No. 40. https://doi.org/10.1007/s11912-016-0530-0

[48] Desai, A.N. and Patel, P. (2020) Stopping the Spread of COVID-19. JAMA, 323, 1516. https://doi.org/10.1001/jama.2020.4269

[49] Abany, Z. (2020) Coronavirus: The Tide Is Coming for Medicinal Cannabis.

[50] Hill, K.P. (2020) Cannabinoids and the Coronavirus. Cannabis and Cannabinoid Research, 5, 118-120. https://doi.org/10.1089/can.2020.0035

[51] Le, J. (2019) Overview of Pharmacokinetics. MSD MANUAL.

[52] Millar, S.A., Stone, N.L., Yates, A.S. and O'Sullivan, S.E. (2018) A Systematic Review on the Pharmacokinetics of Cannabidiol in Humans. Frontiers in Pharmacology, 9, Article No. 1365. https://doi.org/10.3389/fphar.2018.01365

[53] Klumpers, L.E. and Thacker, D.L. (2019) A Brief Background on Cannabis: From Plant to Medical Indications. Journal of AOAC International, 102, 412-420. https://doi.org/10.5740/jaoacint.18-0208

[54] Lucas, C.J., Galettis, P. and Schneider, J. (2018) The Pharmacokinetics and the Pharmacodynamics of Cannabinoids. British Journal of Clinical Pharmacology, 84, 2477-2482. https://doi.org/10.1111/bcp.13710

[55] Grotenhermen, F. (2003) Clinical Pharmacokinetics of Cannabinoids. Journal of Cannabis Therapeutics, 3, 3-51. https://doi.org/10.1300/J175v03n01 02

[56] Kis, B., Ifrim, F.C., Buda, V., Avram, S., Pavel, I.Z., Antal, D., et al. (2019) Cannabidiol-From Plant to Human Body: A Promising Bioactive Molecule with MultiTarget Effects in Cancer. International Journal of Molecular Sciences, 20, Article No. 5905. https://doi.org/10.3390/ijms20235905

[57] Lucas, C.J., Galettis, P., Song, S., Solowij, N., Reuter, S.E., Schneider, J., et al. (2018) Cannabinoid Disposition after Human Intraperitoneal Use: An Insight into Intraperitoneal Pharmacokinetic Properties in Metastatic Cancer. Clinical therapeutics, 40, 1442-1447. https://doi.org/10.1016/j.clinthera.2017.12.008

[58] Heuberger, J.A., Guan, Z., Oyetayo, O.-O., Klumpers, L., Morrison, P.D., Beumer, T.L., et al. (2015) Population Pharmacokinetic Model of THC Integrates Oral, Intravenous, and Pulmonary Dosing and Characterizes Short- and Long-Term Pharmacokinetics. Clinical Pharmacokinetics, 54, 209-219.

https://doi.org/10.1007/s40262-014-0195-5 